Anales del Seminario de Historia de la Filosofía

ISSNe: 1988-2564

http://dx.doi.org/10.5209/ASHF.56800

\title{
Del artificio natural de la política
}

\author{
José Sánchez Tortosa ${ }^{1}$
}

Recibido: 30/06/2016. Aceptado: 14/06/2017

Resumen. El análisis de los fundamentos conceptuales de lo político en la obra de Aristóteles exige una contextualización etimológica, histórica y filosófica de sus términos clave y vincularlo al marco general del sistema ontológico aristotélico. Desde esa plataforma, es posible abordar el patrón teórico propuesto, principalmente, en los libros I y III de la Política, para medir el grado de desviación o de aproximación con respecto a la línea vectorial teleológica de lo político: el gobierno correcto con vistas al bien común, así como su aplicación para un diagnóstico preciso de los fenómenos políticos de la Historia y de nuestros días.

Palabras clave: Aristóteles; política; racionalidad; materialismo; teleología; biopolítica.

\section{[en] On natural artifice of politics}

\begin{abstract}
An etymological, historical and philosophical contextualization of the key terms in Aristotle's work is required to analyse the conceptual foundations of politics, besides the link to the general frame of the Aristotelian ontological system. From this platform, it is possible to face the theoretical pattern offered by Aristotle, mainly, in books I and III of Politics, in order to measure the degree of deviation or approach to the teleological vectorial line of politics: the right government in order to achieve the common wealth, and its application to an accurate diagnosis of the political phaenomena of History and up to the present.
\end{abstract}

Keywords: Aristotle; politics; reason; materialism; teleology; biopolitics.

Cómo citar: José Sánchez Tortosa (2017): “Del artificio natural de la política”, en Anales del Seminario de Historia de la Filosofia 34 (3), 551-569.

Como exige todo gran sistema filosófico, la investigación sobre la política no puede desvincularse de la ontología general del mismo. Sin establecer las conexiones entre la Física y la Política en el caso de Aristóteles, fijando el encaje de lo político en lo físico y, a su vez, en lo ontológico, como campo acotado suyo, como uno de sus casos o expresiones, la comprensión del análisis resulta inviable. Aquí, el vocablo Naturaleza (physis), polisémico, confuso, metafísico, desempeña una función clave que requiere la redefinición del mismo desde los parámetros establecidos por la propia metafísica aristotélica. Así pues, para afrontar el estudio de los mecanismos de

$1 \quad$ Universidad Complutense de Madrid.

josesancheztortosa@gmail.com

ORCID 0000-0001-5726-0338 
poder y de la gestión y estabilidad $\left(\right.$ eutaxia $\left.^{2}\right)$ de los regímenes políticos, se impone la necesidad de determinar el sentido físico y, por continuidad ontológica, político de la noción de naturaleza en Aristóteles. Con afán de ensayar una definición positiva de lo natural, que, sin forzarlo conceptualmente, permita su comprensión en relación con lo político, sugiero la lectura presentada por el profesor Gustavo Bueno 3 según la cual lo natural alude a las líneas vectoriales que marcan la dirección (física, biológica, política...) de los movimientos, cambios o procesos de los seres que, amontonándose, saturan la realidad. En tal sentido, habría que entender lo natural como la racionalidad estructural, definida en cada campo según sus parámetros de referencia, de cada conglomerado de objetos conectados entre sí, a su vez desconectado en parte de cada uno de los demás conglomerados, sometidos todos ellos, sin embargo, a la impronta teleológica múltiple que les da una unidad ontológica y un orden que no pueden reducirse a lo físico (meta-física). El componente teleológico queda, así, atenuado, precisado, confinado a la dimensión inmanente de los procesos físicos, biológicos y, en el caso que nos ocupa, ese momento o variante específica de lo biológico que es lo político, como condición de lo antropológico. De este modo, la lectura trivialmente ecológica de Aristóteles, esto es, valorativa y sustancialista, queda neutralizada por una visión menos pretenciosa y nebulosa, capaz de barrer cualquier tentación idealista o metafísica (y valorativa) que vea en La Naturaleza una unidad sustantiva dotada per se de una bondad fuera del rango de lo humano. Esta lectura de la teleología aristotélica permite superar la confusión con la cual esa fantasmagoría pseudoconceptual, el paralogismo eidético Naturaleza, ofusca el análisis y le niega la claridad necesaria.

Aquí, es obligado referirse al problema de la oposición physis-nómos, conflicto mayor en la trifulca platónica contra la sofística. La ley no es, de hecho, históricamente natural (pero aquí topamos con la indefinición de la expresión de la que estamos tratando de deshacernos: natural), como acaso sostendría toda visión mitológico-teológica del poder político y de la ley legitimada por la tradición. Pero tampoco puede admitirse, contra el convencionalismo sofístico, que no hay nexo alguno entre naturaleza (o racionalidad) y ley, siquiera potencialmente, como posibilidad o dynamis. Ni toda ley es mera convención ni es tampoco herencia eterna de los dioses. Ni se identifica plenamente con lo natural, ni está absolutamente desconectado de ello. La ley es ficción política, artesonado del poder cuya virtud técnica reside en su racionalidad, definida por Aristóteles, precisamente, según la ecuación "ley es razón sin deseo"4. En función de este marco teórico se podrá vislumbrar el uso analítico que de la noción de naturaleza hace Aristóteles en su aplicación a lo político, disipando en lo posible la niebla conceptual que se extiende sobre estas cuestiones. Ésta es la plataforma que impulsa el siguiente trabajo de lectura y anotación del texto de referencia. El comienzo del tratado aborda una taxonomía o catalogación de los fenómenos categoriales que concurren en el espectro de su estudio, lo político, vinculados, por tanto, a los modos de organización social de los grupos de aquello designado genéricamente en griego como ánthropos, en función del encuadre filosófico indicado. Tal clasificación se sustenta en lo que podríamos considerar diferencias cualitativas o es-

2 "no debe considerarse democrático ni oligárquico aquello que haga que la ciudad se gobierne más democrática u oligárquicamente, sino lo que la haga durar el mayor tiempo posible.” (ARISTÓTELES, Política, VI, 1320a, Gredos, trad.: Manuela García Valdés)

http://www.fgbueno.es/act/efo031.htm

$4 \quad$ Política, III, 1287a. 
pecíficas (eidei), es decir, no meramente cuantitativas, entre gobernante (politikòn), rey (basilikón), administrador de la casa (oikonomikón) y amo de esclavos (despotikón). Las diferencias entre estos casos son estructurales, o dicho de otro modo, se basan en los tipos de relaciones (familiares, tribales, políticas) que configuran las instituciones correspondientes a esas unidades sociales. Para la definición de los mismos y su estudio, Aristóteles recurre al método analítico con el cual diseccionar conceptualmente un material histórico ya dado a su escala geográfica e histórica, de modo que procede a dividirlo hasta sus componentes más simples.

En el marco conceptual sugerido, la unión que forja el origen (arkhés) de la constitución de los diferentes grupos sociales se da por necesidad natural, por esa tendencia o caída de raíz biológica que, con la ceguera propia del organismo activo, busca (o accede a) la respuesta a impulsos cuya consecuencia es la continuidad supraindividual. Se niega, por tanto, de manera explícita prolepsis o decisión consciente en este marco, general a todo proceso biológico. Y, bajo esta misma concepción de lo natural como entramado de vertientes (vectores) que dirigen o encauzan las metamorfosis de los seres vivos en direcciones acotadas, encajan también las jerarquías sociales y políticas. Sólo descontando el sesgo valorativo podrá comprenderse esta analítica bio-política de las relaciones que se ajustan a unas jerarquías impuestas por su naturaleza misma, por la dirección vectorial que constituye a los sujetos enredados en ellas, en las cuales cada elemento (y proceso) va ajustándose o acomodándose a su lugar específico (tópos), teleológica, y no sólo espacialmente, definido. Es en este sentido en el que queda establecida la inferioridad natural (diríamos, vectorial) de los esclavos con respecto a los ciudadanos libres, de los bárbaros con respecto a los griegos ${ }^{5}$. La jerarquización organizativa de lo natural estratifica también ese microcosmos de lo biológico que es lo político. Según esto, las sociedades en estado de barbarie (no digamos ya de salvajismo) están en inferioridad política (natural o vectorial), es decir, en peores condiciones tecnológicas, demográficas, institucionales para persistir en el tiempo. Cabe entender que en los casos en que sociedades teóricamente superiores sucumben (como la caída del Imperio Romano) lo que se produce es un desgaste irreparable, demográfico, militar, policial, de una unidad política e histórica dada, siempre precaria y transitoria, nunca eterna. En cuanto a la reconstrucción genealógica de las fases previas a la de la ciudadEstado o ciudadelas, marco de referencia histórico para Aristóteles, se considera la prioridad genética de la casa (oikía prote), como institución dedicada a la satisfacción de las necesidades de la vida cotidiana sobre la tribu o aldea (komé), definida como la unión de varias casas orientada a la satisfacción de las necesidades no cotidianas o diarias. Por eso, la aldea es entendida además, "en su forma natural" (kata physei), como colonia de la casa, cuyos miembros mantienen los vínculos sanguíneos que los anudan en el núcleo familiar. En ellos se sustenta el poder regio. Los lazos sanguíneos son el soporte de la aldea por lo que de ello se deriva necesariamente que el poder en ella se base también en la sangre y que lo ejerza un rey, como sucede en los pueblos bárbaros o étnicos (ethné), aquí en el sentido político de sociedades ancladas en una fase prepolítica, sanguínea o biológica pero no específicamente antropológica del poder. Este es

\footnotetext{
"Es necesario que se emparejen los que no pueden existir uno sin el otro, como la hembra y el macho con vistas a la generación (y esto no en virtud de una decisión, sino como en los demás animales y plantas; es natural [physikòn] la tendencia [ephíesthai] a dejar tras sí otro ser semejante a uno mismo), y el que manda por naturaleza [physei] y el súbdito, para su seguridad. En efecto, el que es capaz de prever con la mente [dianoía] es un jefe por naturaleza y un señor natural, y el que puede con su cuerpo realizar estas cosas es súbdito y esclavo por naturaleza; por eso al señor y al esclavo interesa lo mismo.” (Política, I, 1252a-b).
} 
el motivo por el cual Aristóteles no admite a estos grupos dentro de la categoría de humanos, definida por lo político, esto es, por instituciones que precisan un cierto grado de desarrollo tecnológico e institucional. Si bien no hay humanismo (de raíz cristiana) en el pensamiento aristotélico y griego en general, del que acaso Alejandro Magno y su Imperio quede desmarcado en este sentido, lo cual provocó el distanciamiento entre el joven emperador y su maestro, no hay tampoco racismo. El criterio de demarcación o diferenciación no es biológico o racial. Es bio-político, pero no en el uso que Foucault da a este término, sino en el de la visión de lo político como un fractal ${ }^{6}$, como un caso o subconjunto de lo biológico, no enteramente desgajado de él. Como una desembocadura inexorable del orden de lo real. La ficción de la política, como artificio o constructo humano que se levanta por encima de lo botánico y lo zoológico, es el delta en el cual culmina lo natural, su máximo de complejidad biológica, su corolario teleológico. El funcionamiento organizativo de estos grupos sociales exige un tipo de leyes en los que rigen relaciones de fuerza primitivas, codificadas en la institución de poder de los grupos de edad (ley del más anciano) y en las leyes de parentesco (tabú del incesto). El gobierno de los dioses es de esta naturaleza, patriarcal, es decir, sostenido por lazos sanguíneos, por vínculos sexuales, que son los que conforman el contenido de los relatos míticos. Mientras que el mundo de los dioses olímpicos depende de sus caprichos y excluye una reconstrucción no arbitraria de sus fenómenos, como la esbozada laboriosamente por los protofilósofos presocráticos, también el jefe o rey es, en ese estadio primitivo, un legislador más o menos caprichoso del microcosmos de la sociedad, en su calidad de sujeto operatorio afectivo ajeno al cumplimiento de la ley, ciega racionalidad del orden de lo político, y por debajo de ella. Y en esa imagen se ve reflejada la organización política de los pueblos bárbaros. En paralelo al intento por eliminar la subjetividad irrepetible e insustituible de la divinidad en el orden de los sucesos naturales, la racionalidad filosófica, al reemplazar los lazos de parentesco por leyes de identidad objetiva, en las cuales la subjetividad es cantidad despreciable, habría posibilitado una lectura del poder político no sanguínea. Homero expone como caso paradigmático de salvajismo el de los Cíclopes?

En las sociedades primitivas se puede percibir cómo el modelo estructural, es decir, normativo, jurídico, jerárquico de la casa se perpetua a escala en la aldea. Esto explica la dispersión (sporádes) y la atomización de las sociedades primitivas, reguladas por las leyes de parentesco, y a la condición de conflicto perpetuo entre ellas, que el tabú del incesto, reverso de la división del trabajo, habría posibilitado adormecer o contener en estado latente, al propiciar lazos no bélicos entre ellas ${ }^{8}$.

6 Por fractal entiendo, siguiendo el modelo geométrico, la repetición a diferentes escalas del mismo patrón o estructura básica. En este caso, se pretende aplicar la noción de fractal a la escala especial de lo político dentro de la ontología general aristotélica (biológica, física y metafísica), como el marco de líneas maestras que trazan las tendencias vectoriales de los cuerpos sometidos a movimiento y cambio en diferentes planos categoriales.

"Desde allí, con dolor en el alma, seguimos bogando hasta dar en la tierra que habitan los fieros cíclopes, unos seres sin ley (áthemíston). Confiando en los dioses eternos, nada siembran ni plantan, no labran los campos, mas todo viene allí a germinar sin labor ni simienza: los trigos, las cebadas, las vides que dan licor generoso de sus gajos, nutridos tan sólo por lluvias de Zeus.

Los cíclopes no tratan en juntas ni saben de normas de justicia; las cumbres habitan de excelsas montañas, de sus cuevas haciendo mansión; cada cual da la ley a su esposa y sus hijos sin más y no piensa en los otros." (Odisea, IX, 105-115, Gredos, trad.: José Manuel Pabón)

8 "Pero es Maine el primero en subrayar, de forma clara, que el parentesco proporcionaba el principio básico de organización de la sociedad primitiva, y fue el análisis de McLennan sobre la exogamia y endogamia el que marcó el comienzo de la discusión en torno al origen de la universal prohibición del incesto dentro de la familia nuclear: "puesto que en las condiciones de aquellos tiempos la misma manera de obtener una mujer sujeta y 
No deja de resultar llamativo hasta qué punto hoy día la tentación del nepotismo, del fortalecimiento del poder por medio de los lazos familiares, con la consecuente fidelización de sus agentes al objetivo compartido de perpetuarse en el mando, sigue vigente en el ámbito de lo público y en el de lo privado. Y no ya en lo que hoy es designado como monarquías, sino también en formaciones y gobiernos reputados como republicanos y en los niveles más bajos de la escala política: desde lo estatal hasta lo municipal o lo gremial.

Con la consecución de la autosuficiencia (autarquía) se alcanza ese grado de sofisticación histórica y genealógica que puede ya ser considerado, según este recorrido, como propiamente político, pero que, por los mismo motivos, requiere unas condiciones técnicas y materiales concretas. Por ejemplo, unos límites territoriales y demográficos que permitan su subsistencia, su resistencia ante las amenazas externas y los conflictos internos. En este escrúpulo técnico encajaría el rechazo teórico (conceptual) y práctico (histórico) al macroestado o Imperio, acaso asimilable más al modelo del estado de barbarie que al de la polis propia de la civilización griega, según Aristóteles ${ }^{9}$. En esa oscilación taxonómica, no tabulada más que en el momento del análisis categorial, es decir, al aplicar la plantilla conceptual que Aristóteles sugiere, se agitan y encajan los regímenes políticos realmente existentes, con los matices que en cada caso sea pertinente establecer.

Pero lo político tampoco puede separarse de lo ético, componentes ambos de las funciones biológicas específicas de la forma de vida hablante. La buena vida, concebida como finalidad (racional, ergo natural) de la polis, precisa un marco institucional en el cual, dominada la escritura y los rudimentos de la discusión dialógica (jurídica, política, científica, académica), puedan desarrollarse al máximo las potencialidades para las cuales el animal simbólico está genéticamente (naturalmente) diseñado ${ }^{10}$. El Lógos, la capacidad para discernir lo justo de lo injusto, lo verdadero de lo falso, el concepto del mito, es el arkhé de lo político, de esos complejos de relaciones de muy distintos tipos que cristalizan en el Estado.

Sólo desde este prisma conceptual podrá evitarse la confusión acerca del carácter natural de la pólis, del Estado. Lo político es una tendencia antropológica que discrimina jerárquicamente formas de vida diferentes en el panorama de la biología. No cabe, por ello, negar lo político más que en dos límites, fuera de los cuales no hay humanidad, esto es, civilización: Los dioses, por exceso. Las bestias, por defecto. En ambos casos, el sujeto apolítico no puede ser más que amante de la guerra, viviendo en un conflicto incesante (heraclíteo), que sólo los engranajes vectoriales (naturales, racionales) de las sociedades políticas (con Estado) pueden apaciguar someramente, siempre en estado perpetuo de precariedad, en peligro de descoserse, como la Historia enseña. Sin ley, sin justicia, sin Estado, el hombre, la mejor de las formas de vida, es la peor de las bestias ${ }^{11}$. A expensas de la arbitrariedad afectiva y sentimental,

esclavizada sería a través de la captura; y la prohibición que se aplicara a la captura se aplicaba al matrimonio. El matrimonio con una mujer de la misma ascendencia sería un crimen y un pecado. Sería incesto.

Será, sin embargo, el ya mencionado Tylor el primero en comprender el incesto en función de sus posibles ventajas de carácter cultural. La exogamia, para Tylor, es una especie de alianza que autoconserva el entramado político, puesto que sólo a través del matrimonio es posible establecer alianzas de modo que la sociedad funcione y mantenga sus límites máximos y mínimos.” BUENO, G. y HIDALGO, M., Symploké, Madrid, Júcar, 1987, p. 427.

9 Política, VII, $1326 \mathrm{~b}$.

10 Ética a Nicómaco, I, 5, 1097b14, Gredos, trad.: Julio Pallí Bonet.

11 Política, I, 2, 1253a. 
cristalizada ideológicamente en populismos y fanatismos de amplio espectro, sin la horma precaria de la racionalidad de la ley, de su impersonalidad objetiva, los humanos, dotados tecnológicamente más que otras especies, son capaces de los mayores desastres. Los genocidios, esa fatalidad de las sociedades históricas, que, lejos de haberse superado, persisten como un impulso recurrente, confirman el diagnóstico aristotélico formulado hace 25 siglos. Sin Estado no hay justicia. Fuera del Estado no hay ley. El Estado es condición necesaria, pero no suficiente, para la justicia. El salvaje carece de ley, es pura impulsividad botánica. El bárbaro carece de ley política, aunque tiene ley sanguínea o tribal, esto es, animal. Por todo ello, la fuente de la que emana la ley y la justicia para Aristóteles no puede ser ningún ente trascendental. Ni Naturaleza, hipostasiada por encima de los divergentes y aun conflictivos procesos múltiples que concurren en los cuerpos dotados de movimiento y cambio, ni Dios o dioses que graciosamente encarnen una Justicia eterna, supranatural. Acaso sea útil recordar que, mientras que la noción de Naturaleza se consolida en la modernidad por desplazamiento del Dios Absoluto y asunción de su trono metafísico, dejando intacto su contenido vacío, su función distorsionadora y consoladora, la noción de Naturaleza en el pensamiento griego (lo físico) se erige contra las subjetividades suprahumanas de las divinidades, abriendo la posibilidad de reconstruir a la escala virtual del pensamiento, fragmentos del orden objetivo que determina los procesos dados a la observación. A través del cristianismo, la Naturaleza regresa al seno metafísico de la divinidad, donde permanece firmemente acomodada en la postmodernidad, imponiéndose como un absoluto en la tabla hegemónica de los valores, cuya mera crítica es confinada por la sociedad biempensante a las tinieblas del negacionismo. Semejante conclusión libera de la atribución idealista a un referente moral absoluto, previo o ajeno a esa compleja red de instituciones históricas que llamamos Estado ${ }^{12}$. No hay ley ni justicia sin Estado. No hay, por tanto, libertad fuera de él. El análisis aristotélico devasta, más allá de sus limitaciones conceptuales y empíricas, las ensoñaciones del buen salvaje y de los indigenismos de moda, metafísicas de saldo que se empecinan en la cíclica búsqueda de Absolutos (Dios, Naturaleza, Raza, Nación, Lengua, Pueblo, Gente) que legitimen el delirio político y, consecuentemente, en sus casos más extremos pero no los menos verosímiles, el desastre histórico y el crimen en masa.

En la lectura de Aristóteles hay un problema que suele quedar oculto, un enredo del que no se puede tener noticia hasta un análisis pormenorizado de los textos y de los vocablos griegos fundamentales empleados, así como de su significado histórico y técnico, del que arranca su recorrido filosófico y su potencia conceptual hasta hoy. Por las características políticas de la Atenas clásica y, en general, de la Grecia Antigua, su estudio tiene mucho que decir de nuestras sociedades de masas alfabetizadas en el formalismo de la escuela basura ${ }^{13}$ y de los medios de difusión (y confusión). Las palabras pueblo, multitud, gente, ciudadano, progreso, así como sus reversos tenebrosos (casta, vieja política...), son invocadas constantemente con una carga simbólica preestablecida que suele impedir su definición precisa y que, por ello, contribuye al triunfo de las políticas más perniciosas, por corrupción y, sobre todo, por

12 "La justicia [diké], en cambio, es un valor cívico, pues la justicia es el orden de la comunidad civil [politikés koinonías táxis], y la virtud de la justicia es el discernimiento [krísis] de lo justo." Política, I, 1253a.

13 SÁNCHEZ TORTOSA, J., "La escuela basura", Libertad Digital, 4 de febrero de 2010; "Formalismo pedagógico", Libertad Digital, 29 de julio de 2010. 
fanatismo. En la Política, Aristóteles asume el desafío de precisar una definición de ciudad ( $p o ́ l i s$ ), de régimen político (politeía) y de ciudadano (polités) que sea operativa en el análisis crítico de las formas de gobierno, de las posibles y de las realmente existentes. A estos conceptos se suman dos que, a veces en las traducciones, que emplean a menudo un mismo término para dos palabras griegas distintas, y siempre en el imaginario actual, simulan fundirse en uno solo: pueblo. En griego, no obstante, la palabra de origen latino esconde dos términos dotados de un significado diferente y aun opuesto, según la tesis arriesgada en este trabajo de lectura: demos y pléthos. A continuación, se va a proceder a recorrer el libro III de la Política de Aristóteles en busca de estas aclaraciones que se antojan necesarias e, incluso, de emergencia a escala nacional e internacional ${ }^{14}$, a pesar de la certeza de que tal esfuerzo será estéril.

Es sabido que cuando hablamos de las pólis griegas nos referimos a Estados. Según el dictamen aristotélico, la autarquía, esto es, la independencia económica, militar y territorial, es conditio sine qua non del Estado. Si bien reducidas a límites demográficos y espaciales equivalentes a ciudades actuales más bien pequeñas ${ }^{15}$, las pólis cumplían estos requisitos políticos en el momento en que Aristóteles lleva a efecto esta investigación. De ahí, la definición de ciudad (ciudad-Estado, ciudadela, cantón...) que ofrece en este punto: conjunto de ciudadanos dotado de autarquía ${ }^{16}$. Como resulta claro, esta definición exige, a su vez, definir los términos incluidos en ella. La autarquía fue definida en el libro I, como acabamos de recordar. La noción de ciudadano lleva a Aristóteles a una definición general que pide, sin embargo, precisiones históricas, jurídicas y políticas esenciales. Y todo ello, conduce al concepto genérico de régimen político, también designado como república, traducción del griego politeía, que es concebido como una cierta ordenación (táxis) de los habitantes de la ciudad ${ }^{17} \mathrm{y}$ de las magistraturas (arkhón) ${ }^{18}$.

La definición de ciudadano apela a funciones políticas institucionalizadas, que varían en su aplicación práctica e histórica de unos sistemas a otros. Por eso, no puede definirse con independencia del régimen político del cual es ciudadano. En su expresión más lacónica y general, el ciudadano se caracteriza por participar en las funciones judiciales y en el gobierno. No hace referencia, por tanto, al hecho de ser habitante de un territorio, que es condición necesaria pero no suficiente, ni a la atribución de ciertos derechos, con los que cuentan, por ejemplo, niños y ancianos (jubilados), pero que no son ciudadanos de pleno derecho al estar exentos de ciertas funciones por motivos temporales (biológicos e institucionales) ${ }^{19}$.

En la realidad histórica que Aristóteles tiene a la vista, la ciudadanía está definida por los lazos familiares: ser hijo de padre y madre ciudadanos. En el contexto de ciudades-Estado o ciudadelas, dentro de límites demográficos bastante restringidos, la pertenencia al génos fue medida adoptada con vistas a la democratización de Atenas. Es el caso de Pericles, que propuso, siendo arconte Antídoto y debido al exceso

14 Estas palabras han sido escritas horas después de los atentados yihadistas en Bruselas (22 de marzo de 2016) y en pleno vacío de gobierno en España.

15 "Todos los ciudadanos [de Atenas] participaban de los asuntos públicos, pero no eran más de 20.000 ciudadanos sobre más de 350.000 habitantes: todos los demás eran esclavos y desarrollaban la mayor parte de los trabajos y de las funciones que en nuestro tiempo corresponden al pueblo y a las clases medias." (TOCQUEVILLE, A., citado por CANFORA, L., El mundo de Atenas, Barcelona, Anagrama, 2011, p. 42).

16 Política, III, 1275a.

17 Política, III, $1274 \mathrm{~b}$.

18 Política, III, 1278b.

19 Política, III, 1275a. 
demográfico, la restricción de la ciudadanía a los hijos de padre y madre atenienses ${ }^{20}$, medida que favoreció a las clases popular y media, ya que las viejas aristocracias tenían lazos con familias de las demás pólis griegas e, incluso, no griegas ${ }^{21}$. Tampoco es casual que no pueda concebirse la democracia ateniense sin el hecho de que son los ciudadanos libres los que forman parte del ejército, no los esclavos o los metecos, que sólo lo hacían de manera excepcional. Sin embargo, Clístenes introdujo reformas en sentido contrario que fueron clave para la constitución de la Atenas democrática ${ }^{22}$.

En el análisis de Aristóteles, la nueva distribución de las tribus debilitaba los antiguos lazos sanguíneos y sus privilegios y, de ese modo, fue más fácil ampliar la ciudadanía a libertos, extranjeros, bastardos, etc. Esta reforma organiza la población según criterios territoriales por circunscripciones administrativas, no familiares, haciendo que los linajes o clanes aristocráticos estuvieran esparcidos y disueltos en varias demarcaciones territoriales y se impusiera el interés de toda la comunidad y no de las antiguas familias privilegiadas.

De la descripción histórica, jurídica y política de la condición de ciudadano pasa al análisis conceptual de su fundamento técnico (justo, recto), que no puede desvincularse del análisis del sistema de gobierno. El parámetro que discrimina unos regímenes (desviados) de otros (los rectos o sanos o naturales) es la utilidad, es decir, la finalidad, que es la conveniencia o bien común. Si no se guían por ella, se imponen por la fuerza. Y ambas posibilidades incluyen a la democracia, que puede ser recta (natural) o impuesta (desviada). Si una ley es justa es estable. Si no es estable es que no es justa. El tirano, como la masa hace con los ricos, ejercen el poder por la fuerza (bias). En tal caso, esa ley no es justa propiamente, no es virtuosa, pues no puede serlo un sistema que no perdura en el tiempo, que es más débil, sin perjuicio de ser destructivo (el III Reich fue poderoso y aniquilador pero no estable ni duradero): "La virtud no destruye a quien la posee." ${ }^{23}$ En la física aristotélica, lo violento es lo opuesto al movimiento natural. Por analogía, en política, es lo opuesto (desviado, enfermo) al bien común.

Resulta inexcusable confrontar a Aristóteles, en este punto, con Spinoza. En coherencia con el marco de su ontología general, el Estado es concebido como un individuo compuesto que, a su escala, se conduce según las directrices propias de todo individuo que tiende a perpetuarse en su ser en la medida limitada de sus fuerzas. Derecho natural no se distingue de poder ${ }^{24}$.

20 ARISTÓTELES, Constitución de los atenienses, 26, 4, Gredos, trad.: Manuela García Valdés.

21 CANFORA, p. 145.

22 "Entonces, puesto al frente del pueblo, en el año cuarto después de la caída de los tiranos, siendo arconte Iságoras, primeramente dividió a todos en diez tribus en lugar de las cuatro, con la intención de mezclarlos, para que participase mayor número en el gobierno. (...) Después, formó el consejo de quinientos miembros en lugar de cuatrocientos, cincuenta de cada tribu, que hasta entonces habían sido cien. Por esto no los organizó en doce tribus, para que no resultara la división de acuerdo con las tritías preexistentes, pues de cuatro tribus había doce tritías, y así no se hubiera mezclado la muchedumbre." (Constitución de los atenienses, 21, 2). Véase también CANFORA, p. 68.

23 Política, III, 1281a.

24 "Per ius itaque naturae intelligo ipsas naturae leges seu regulas, secundum quas omnia fiunt, hoc est, ipsam naturae potentiam. Atque adeo totius naturae, et consequenter uniuscuiusque individui naturale ius eo usque se extendit, quo eius potentia; et consequenter quicquid unusquisque homo ex legibus suae naturae agit, id summo naturae iure agit, tantumque in naturam habet iuris, quantum potentia valet." (SPINOZA, B., Tractatus Politicus, II, 4) 
Y en esta línea de una teoría materialista del poder, que arrancaría en la modernidad con Maquiavelo, encaja, no sin paradoja, el dictamen lúcido de Pascal ${ }^{25}$.

Pero ¿no ha de imponerse también por la fuerza el régimen recto? ¿No ha de imponerse por la fuerza la racionalidad (biopolítica) a la animalidad (antipolítica)? De nuevo, la teoría política de Aristóteles obliga a remitirse a su Física. En ella, se considera movimiento violento al que se opone al movimiento natural. De modo que la violencia queda ceñida necesariamente a los parámetros físicos, y en lo tocante a lo humano, biológicos y políticos, en función de los cuales discriminar en cada caso lo violento de lo natural. No hay vida sin violencia. No hay política sin violencia. El criterio discriminador tendrá que ser el fin al servicio del cual sea empleada la fuerza. Lo inane o interesado de condenar la violencia en abstracto queda de relieve. La fuerza que impone un régimen orientado a la dirección teleológica inherente a su condición ontológica, aquí al bien común, será natural, racional (física). Los procesos que impidan, obstaculicen o ralenticen semejante objetivo se oponen violentamente a él, violan esa naturaleza política propia del sistema artificial que llamamos Estado. En el primer caso la ley es cristalización o codificación de la fuerza natural (biopolítica). En el segundo caso, el régimen desviado es materialización de una violencia perversa, de una pulsión desviada del eje vectorial, defectuosa y a la larga menos potente, menos capaz de perdurar. Para entendernos podríamos acordar denominar, dentro de este marco conceptual, fuerza a lo natural y violencia a lo antinatural, en los sentidos explicados ${ }^{26}$. Un sistema político recto es fuerte. Un sistema político desviado es violento.

En este sentido, cabe establecer la anterioridad natural (física) de los regímenes perfectos sobre los desviados, dentro del marco ontológico general en el que el acto (enérgeia o entelécheia) es anterior lógica y ontológicamente, es decir, más perfecto, más acabado, que la potencia (dynamis) y que, por ello, delinea la finalidad vectorial, señala la dirección sin la cual no puede llegar a ser lo que es (en potencia).

Los componentes básicos de esta realidad naturalmente artificial denominada Estado en proceso de transformación según la finalidad correspondiente son territorio y habitantes ${ }^{27}$. Con respecto a los habitantes hay que determinar si conviene que cohabiten distintos linajes (génos) y razas (éthnos) o sólo uno, lo cual es de notable relevancia con respecto al modo de gestión de la población y su relación con el sistema de gobierno, como ya hemos visto. El factor territorial y el demográfico son condiciones necesarias pero no suficientes para la constitución del Estado ${ }^{28}$. El Estado es la objetivación de unas condiciones económicas, tecnológicas e históricas que permitan la buena vida, esto es, el desarrollo de las ciencias, las artes, el comercio, el tiempo libre (liberado del trabajo manual o servil), la política y la abogacía como ejercicios del hombre libre (liberado del tiempo de trabajo). Es en este marco institucional en el cual el sujeto humano puede ser bueno: buen hombre (virtud ética) y buen ciudadano (virtud política) y en el cual puede darse un buen sistema de gobierno.

25 "ne pouvant faire que ce qui est juste fût fort, on a fait que ce qui est fort fût juste.” (Pensées, L103 B322). El materialismo de Pascal se da a escala de lo mundano y en el abismo ontológico que pone al hombre a distancia infinita de lo Absoluto: "le fini s'anéantit en présence de l'infini et deviént un pur neant." (L418 B233: "lo finito se anula en presencia de lo infinito y deviene una pura nada."). Y Góngora, claro: "hay distancia más inmensa de Dios a hombre, que de hombre a muerte." (Al nacimiento de Cristo, nuestro Señor, 1600).

26 En griego se suele emplear bías para ambos vocablos.

27 Política, III, 1276a.

28 Política, III, 1280 b. 
La virtud del buen ciudadano se define, sin perjuicio de sus diferentes funciones dentro de la comunidad, por un fin común: la seguridad (o bienestar) de la comunidad (sotería tes koinonías), es decir, del régimen político. Por eso, la virtud política depende del régimen. No será la misma para el ciudadano de cada régimen ya que la virtud ciudadana se define como función con vistas a un fin, pero ese fin, la estabilidad del Estado, se puede alcanzar por diferentes medios, es decir, hay distintas formas de gobierno, y depende de factores históricos, demográficos, económicos, etc. Ahí radica la diferencia entre virtud ética y virtud política o ciudadana, entre hombre (andrós) y ciudadano (polités) ${ }^{29}$, según la presenta Aristóteles. La virtud política está vinculada al Estado, concebido como cristalización material e institucional de poder en una sociedad histórica dada, con unas condiciones concretas, no en abstracto. La virtud ética se repliega, en Aristóteles, al rincón del individuo, que no puede serlo sin Estado, pero que no es propiedad del Estado.

Esa diferencia parece diluirse en la Constitución francesa de 1791 y en la de 1793, firmadas como Declaración de los derechos del Hombre y del ciudadano. En ellas, el estatuto de ciudadano (francés) viene a ser el cumplimiento de la condición de lo humano, cuyos derechos son concebidos como naturales (pero no físicos o vectoriales, en el sentido aristotélico indicado), que la República francesa garantiza, aboliendo la servidumbre feudal del Ancien Régime ${ }^{30}$.

Pero esos derechos humanos y cívicos se sostienen, y se pretenden legitimar rousseaunianamente, sobre un supuesto metafísico, el pueblo soberano y la voluntad general, de los cuales la Nación política es expresión histórica y cuyo objetivo se pretende sea nada menos que la "felicidad común"31.

Ese fantasmagórico ente monstruoso (la voluntad general del Pueblo) oculta, con un voluntarismo catastrófico que identifica el Bien con el Pueblo, que no puede equivocarse ("No puede ordenar sino lo que es justo"), una realidad fragmentaria, con elementos heterogéneos, en continuo conflicto de intereses incompatibles.

En el artículo 4 del Acta constitucional de 1793 se determina el estatuto del ciudadano ${ }^{32}$.

Como se puede apreciar, la condición de ciudadanía tiene su origen en el nacimiento dentro del territorio de la Nación, exige requisitos de edad y, en relación con

29 “oúk àn eín mía àretè polítou kaì àndròs àgathou.” (Política, III, 1277a).

30 "Art. 1. Los hombres nacen y permanecen libres e iguales en sus derechos. Las distinciones sociales no pueden estar fundadas más que en la utilidad común.

Art. 2. El fin de toda asociación política es la conservación de los derechos naturales e imprescriptibles del hombre. Estos derechos son la libertad, la propiedad, la seguridad y la resistencia a la opresión." (Artículos 1 y 2 de la Constitución de 1791).

31 “Art. 3. El principio de toda soberanía reside esencialmente en la Nación. Ningún cuerpo, ningún individuo puede ejercer autoridad si no emana expresamente de ella." (Art. 3 de la Constitución de 1791)

"Art. 1. El fin de la sociedad es la felicidad común. El gobierno ha sido instituido para garantizar al hombre el goce de sus derechos naturales e imprescriptibles.

Art. 3. La ley es expresión libre y solemne de la voluntad general. Es la misma par todos, tanto cuando protege como cuando castiga. No puede ordenar sino lo que es justo y útil para la sociedad; sólo puede prohibir lo que sea perjudicial para la misma.

Art. 25. La soberanía reside en el pueblo; es una, indivisible, imprescriptible e inalienable." (Artículos 1, 3 y 25 de la Constitución de 1793).

32 "Todo hombre nacido y domiciliado en Francia, mayor de veintiún años cumplidos; todo extranjero mayor de veintiún años cumplidos, que, domiciliado en Francia desde hace un año, vive aquí de su trabajo, o adquiere una propiedad, o se casa con una francesa, o adopta un niño, o alimenta a un viejo; en resumen: todo extranjero que el cuerpo legislativo piense que ha merecido bien de la humanidad, está en posesión de los derechos de ciudadano francés." 
los extranjeros, precisa unas condiciones económicas y finalmente éticas, vinculadas a ese magma en el que se diluye la ciudadanía: los derechos humanos. En lo relativo a los extranjeros a los que se les proporciona ciudadanía, asunto de la mayor actualidad, ya Aristóteles observa el caso de algunas democracias que admiten como ciudadanos a los extranjeros (los metecos, en la Atenas clásica, que no los admitía como tales) debido a la escasez demográfica, por lo que en las fases de recuperación se retorna a legislaciones más restrictivas ${ }^{33}$.

Un parámetro esencial para determinar la condición del ciudadano es la igualdad, concepto que también precisa ser definido en función de criterios específicos, no en abstracto. Aquí aparece de nuevo la distancia entre virtud ética y política, que no pueden entenderse por separado pero que tampoco se identifican. La constatación de que "es imposible que todos los ciudadanos sean iguales" apunta a esa distancia. Por eso, aunque la virtud del ciudadano han de tenerla todos, por obligación social, asumida por educación o miedo o impuesta por la fuerza de las sanciones administrativas, la ética no la tendrán todos ni será imprescindible que la tengan. Ahí surge el conflicto entre una y otra, muchas veces irresoluble. La ciudad está compuesta de elementos distintos y con intereses incompatibles. Aquí recurre Aristóteles al paralelismo, que está ya en Platón, Estado-individuo. Concibe el cuerpo social como traslación a escala del cuerpo individual, dotado de alma y de las tres funciones correspondientes, que en el Estado se dan como sectores socio-económicos: economía, ejército, gobierno. El alma es función orgánica (biológica), que por su diseño genético define al humano por ser capaz de razón, además de sentimientos y deseos en su unión inseparable con el cuerpo ${ }^{34}$. De modo análogo se da este paralelismo en la esfera de lo político, de lo doméstico y de lo económico, planos en los que se impone una jerarquía bio-política, unas inercias vectoriales que estratifican esas estructuras por su peso específico dentro de la ontología especial de lo político ${ }^{35}$. En cada una de ellas la preponderancia de lo racional sobre lo animal y lo vegetal marca la dirección natural (biológica y política) hacia la finalidad específica. Como en el dictamen platónico, según se verá, dejar la dirección o el mando de la sociedad en poder de lo sentimental, esto es, del ejército como defensor de la patria, del territorio, que vincula sentimentalmente, consanguíneamente a los sujetos, o de los apetitos, es decir, de los productores de los bienes necesarios para la subsistencia biológica, es extraviarse y asegurar el desastre político. Dicho en términos práctico-políticos, los lazos familiares, las alianzas militares por necesidades defensivas o las relaciones por mero interés mercantil no son lo suficientemente sólidos como para garantizar el bienestar de la sociedad política ${ }^{36}$ y serán proclives a fanatismo y corrupción. La alternativa, en sus complejas aplicaciones concretas a cada Estado, es que el gobierno sea competencia de la función racional de la sociedad. Los sentimientos, sin la regulación de la racionalidad política, producen fanatismo. Los deseos, corrupción. La única vía para la estabilidad del Estado es la de la racionalidad común de la ley,

33 Politica, III, 1278a.

34 “El alma [psychés] está dividida en dos partes, una de las cuales posee por sí misma razón [logón kath’autó], y la otra no la posee por sí misma, pero es capaz de obedecer a la razón.” (Política, VII, 1333a)

35 "Por naturaleza [physei] la mayoría de las cosas tienen elementos regentes [árchonta] y elementos regidos [árchómena]." (Política, I, 1260a)

36 Política, III, $1280 \mathrm{~b}$. 
siempre frágil, precaria, objetivada en grados limitados y variables, siempre lejos de la pretensión utópica de la perfección ${ }^{37}$.

Aquí está realizado el principio de symploké38 en la esfera de lo político, clave de bóveda del sistema filosófico platónico y del decir filosófico en general, plataforma crítica contra dogmatismos y fundamentalismos y contra relativismos y nihilismos. Sobre este principio se erige el discurso capaz de negar la posibilidad de un totalitarismo onto-político, que reduce toda realidad a un principio único de gobierno (el poder concebido como emanación de una trascendencia intocable, Dios, La Naturaleza, La Humanidad, El Pueblo, La Historia...). Pero también neutraliza la posibilidad de una dispersión absoluta del poder en las supuestas individualidades autónomas, nunca completamente desconectadas entre sí (la ensoñación del libre albedrío individual de la voluntad). Toda realidad finita oscila entre el cero y el infinito, in medias res, sometida a conexiones y discontinuidades que excluyen tanto la reducción de lo real a un único principio como la disolución completa de los elementos. En este tránsito dialéctico en convulsión constante se mueven también los procesos políticos.

Tampoco puede ser la misma la virtud del ciudadano y la del gobernante (árkhonta). La del ciudadano se define como la capacidad de mandar y obedecer bien, es decir, servir a la ciudad, acatando sus leyes, y participar en su organización, pero "No puede mandar bien quien no ha obedecido." ${ }^{39}$ Por eso, la virtud característica del que manda es la prudencia (phrónesis), y eso requiere una formación técnica, teórica y práctica específica.

Como se puede apreciar, el contenido que Aristóteles da a la virtud política se rige por condiciones precisas de carácter jurídico, institucional y económico. Así, dicho esto en cuanto a la intervención del ciudadano en los planos ejecutivo, judicial y legislativo, hay que precisar las condiciones económicas y laborales, en función de las cuales se distinguen los ciudadanos libres (exentos de trabajos serviles) de los

37 "Y así la ciudad nuestra y vuestra vivirá a la luz del día y no entre sueños, como viven ahora la mayor parte de ellas por obra de quienes luchan unos con otros por vanas sombras o se disputan el mando como si éste fuera algún bien. Mas la verdad es, creo yo, lo siguiente: la ciudad en que estén menos ansiosos por ser gobernantes quienes hayan de serlo, ésa ha de ser forzosamente la que viva mejor y con menos disensiones que ninguna; y la que tenga otra clase de gobernantes, de modo distinto." (PLATÓN, República, 520 c-d, Gredos, trad.: Conrado Eggers).

38 "Teeteto: Es de temer que el no-ser esté entrelazado con el ser mediante una combinación [symplokèn] de este tipo, lo cual es muy insólito. (...) Extranjero: ¿Dejaremos acaso de poner en relación al ser con el cambio y con el reposo, y toda cosa con toda otra cosa, como si existiesen sin mezcla y fuese posible un intercambio mutuo, y las consideraremos así en nuestro razonamiento? ¿O reuniremos todas las cosas en una sola, como si fuese posible para ellas comunicarse recíprocamente? ¿O pondremos en relación a unas sí, y a otras no?” (Sofista, 240b-c-251d, Gredos, trad.: Néstor Luis Cordero); "Extranjero: Pues, mi buen amigo, intentar separar todo de todo es, por otra parte, algo desproporcionado, completamente disonante y ajeno a la filosofía [áfilosóphon]. Teeteto: ¿Qué? Extranjero: La aniquilación más completa de todo tipo de discurso [lógon] consiste en separar a cada cosa de las demás, pues el discurso se originó, para nosotros, por la combinación [symplokèn] mutua de las formas. (...) Extranjero: Pero, en realidad, ha llegado el momento en que debemos ponernos de acuerdo acerca de qué es el discurso, pues si excluyéramos en absoluto su existencia, no seríamos siquiera capaces de hablar. Y lo excluiríamos si admitiéramos que no hay ningún tipo de mezcla de nada con nada." (259e-260b); "Extranjero: Así, del mismo modo que algunas cosas se combinan mutuamente y otras no, también en lo que respecta a las significaciones sonoras, por su parte, algunas no se combinan, y otras sí, dando de este modo origen al discurso." (262d-e) "Sócrates: Por consiguiente, si ni todo es para todos igual al mismo tiempo y en todo momento, ni tampoco cada uno de los seres es distinto para cada individuo, es evidente que las cosas poseen un ser propio consistente. No tienen relación ni dependencia con nosotros ni se dejan arrastrar arriba y abajo por obra de nuestra imaginación, sino que son en sí y con relación a su propio ser conforme a su naturaleza." (Crátilo, 386e Gredos, trad.: J. L. Calvo).

39 Política, III, $1277 \mathrm{~b}$. 
jornaleros (trabajo para la comunidad) y de los esclavos (trabajo para un particular). Hay sistemas de gestión política en los cuales sólo tendrán carta de ciudadanía los primeros, como las aristocracias, que rigen la condición de ciudadano según el mérito o la dignidad (axían), por lo que se excluyen las labores manuales. Otros, incluirán también a los segundos, como las oligarquías, en las que la ciudadanía se obtiene por el pago de impuestos, así que los jornaleros entrarían en esa condición. De modo que estas categorías laborales se combinan con categorías jurídicas y políticas en el entramado institucional del Estado.

Estas acotaciones acerca del concepto de ciudadano conducen al análisis y clasificación de los regímenes políticos:

La taxonomía de los regímenes políticos ${ }^{40}$ no puede entenderse sin referencia a la noción de finalidad vectorial, tal como ha sido indicado. El régimen político se define por la gestión del gobierno (políteuma), es decir, del poder soberano (kyrías). La valoración técnica de dicha gestión dependerá del grado de rectitud en su orientación con vistas al fin del bien común.

Las variantes orto-políticas, rectas, son, por tanto, las que se desarrollan dentro de los cauces direccionales orientados a la finalidad política, a la perfección política, el bien común ${ }^{41}$. Las variantes desviadas (parekbasis), patológicas, infectas o defectuosas, son las que se desarrollan alejándose de la línea que conduce al bien común. Esa perversión es técnica, en primer lugar, política, por tanto, y biológica (o biopolítica), debido a la impronta de la animalidad (deseos y pasiones) que se impone a la racionalidad política, específica de lo humano. Los regímenes desviados no son contrarios a la naturaleza por ser artificiales, sino por no serlo suficientemente, es decir, por desviarse de su naturaleza propia, que tiende al laborioso artesanado del bien político y que, por tanto, los define en función de su télos. Son patologías políticas, anomalías que la naturaleza, como conjunto de procesos físicos, incluye, pero que se extravían con respecto al camino que su finalidad específica, distintiva establece, como la enfermedad es desviación natural del curso de la salud que la naturaleza artificial de la técnica médica conserva o recupera. Un individuo complejo (no absoluto o atómico) cae en perversión si se impone una función inferior en la escala de la complejidad biológica de los seres orgánicos a costa de una superior, más rica y más potente. En el caso de los sistemas políticos, como individuos compuestos o complejos, también constituyen entramados de líneas vectoriales que se orientan a un fin, en conflicto con otros fines que también operan en ellos. Ese fin está biológicamente determinado y su desviación supone la preeminencia de tendencias más rudimentarias o primitivas, animales por analogía con el individuo humano en el caso que nos ocupa. La salida de los cauces que se dirigen al objetivo (télos) del bien común, del máximo bienestar o beneficio para la ciudad como tal (y no sólo para la mayoría), rompe con su naturaleza (su esencia, su dirección), no con La Naturaleza en su totalidad, idea que el sistema ontológico de Aristóteles reemplaza por el heterogéneo sistema de una multiplicidad de finalidades vectoriales a distintas velocidades y en conflicto constante.

En esta taxonomía, operan dos criterios de demarcación y definición. Un criterio cuantitativo en relación al depositario de la soberanía (¿Quién manda?): Uno, una minoría, la mayoría. Y un criterio cualitativo en relación al grado de cumplimiento

40 Política, III, $1278 \mathrm{~b}$.

41 Política, III, 1279a. 
de la finalidad específica de la ciudad y, por tanto, de su sistema de gestión (¿Para quién?): si se ejerce el poder con vistas al interés común (koiné) o con vistas al interés particular (idión). El criterio cuantitativo es accidental (symbebekós). El sustantivo es el criterio cualitativo, que permitirá medir el grado de conveniencia y eficacia política (virtud) de cualquier sistema de gobierno dado.

Los regímenes rectos reciben la siguiente y variable catalogación: Monarquía (basileian), Aristocracia, Politeía (nombre común a todos los regímenes que suele traducirse por República). Los desviados son Tiranía, Oligarquía y Democracia (a veces, Demagogia).

El término monarquía suele ser empleado en tono neutro, como mera designación del gobierno de uno, extremo límite que no habrá de darse en la realidad empírica. La distinción entre los vocablos griegos tiranos y basileus se establece en función del criterio cualitativo, si bien se basa en la procedencia del monarca. El primero hace referencia a un rey elegido. El segundo, a uno que detenta el poder por vía hereditaria. De modo que, para la mentalidad convencional de la Antigua Grecia, el tirano era más bien el rey extranjero o el jefe militar que era seleccionado o se imponía por la fuerza, muchas veces apoyado por amplios sectores de los ciudadanos, por lo que, al cabo, cumplía los rasgos característicos del demagogo. El peso peyorativo del término tirano fue imponiéndose por las políticas concretas y los abusos de poder que en tales situaciones se dieron con frecuencia. De ahí que Aristóteles lo use para la forma desviada o idiota de la monarquía. El basileus era, por el contrario, el rey considerado legítimo por vía sanguínea o dinástica ${ }^{42}$.

La democracia, por su parte, supone, según esto, una desviación de la politeía $a^{43}$. La crítica aristotélica a la democracia presenta aspectos comunes con la platónica, pero resulta acaso más matizada y se apoya no sólo en el armazón conceptual de su sistema sino en el estudio histórico de las formas de gobierno que han recibido ese nombre hasta el momento en el cual lleva a cabo esta investigación.

Toda forma de Estado se agita en medio de una gradación cuyos extremos límite son la forma sana de cada modelo (Monarquía, Aristocracia y Politeía) y sus modos patológicos (Tiranía, Oligarquía y Demagogia o Demokratí $a^{44}$ ). No hay fundamentalismo o sustancialismo en la política de Aristóteles. Cada sistema será mejor o peor no tanto en función de quién detente el poder, de cuál sea el fundamento de su soberanía, que no deja de ser accidental, sino de con qué precisión técnica cumple el objetivo cualitativo fijado para el Estado. La competencia técnica es el factor decisivo. En ella radica la virtud. La identidad (personal, familiar, social, económica...) del que gobierna es por completo secundaria con vistas al bien común, si bien resulta esencial con vistas al interés propio y la perpetuación en el poder. $\mathrm{Su}$ invocación suele ocultar, en nuestras sociedades, políticas nefastas y contribuyen a desviar la mirada de la eficacia política real del mando, de su corrupción o ceguera ("pero son de los nuestros...") ${ }^{45}$. De hecho, ni siquiera la ley está exenta de ajustarse a las condiciones concretas de cada sistema: "las leyes deben establecerse de acuerdo con el régimen." ${ }^{6}$ No hay leyes eternas o puras que puedan ser aplicables a cualesquiera situaciones reales. La ley política es racionalidad artesanal, aproximada pero objeti-

42 Cf. FERNÁNDEZ URIEL, P., Historia Antigua Universal, II. El Mundo Griego, Madrid, UNED, 2014, p. 236.

43 Política, III, 1279b.

44 "tyranída mèn basileías óligarchían dè áristokratías demokratían [30] dè politeías" (Política, IV, 1289a).

45 Populismos y nacionalismos encajan en este diagnóstico.

46 Política, III, $1282 \mathrm{~b}$. 
va, no es mero capricho ni encarnación de la Gracia santificante o de la Naturaleza redentora.

En el ejercicio del poder por parte de cada régimen estudiado, se pueden observar diferencias de facto, que son cristalización concreta de la definición teórica y genérica de partida según la finalidad del Estado. Así, la aristocracia vendría a definirse históricamente por la virtud, la oligarquía, por la riqueza y la democracia, por la libertad ${ }^{47}$. Ninguno de ellos es bueno o malo per se. Por eso, como veremos, lo más beneficioso políticamente es, para Aristóteles, una combinación de todos ellos ${ }^{48}$, que no deja de ser en cierto modo lo que sucede de hecho en nuestras sociedades, por mucho que se enmascare la cuestión con los adornos de la santa democracia, invocada como mantra para cualquier cosa. Pero una sociedad democrática no se forma por la unión de partes democráticas, sino por la unión de resortes que, combinados, permiten condiciones de democracia, igual que los fonemas que componen una palabra no tienen significado por separado, sino sólo en su correcta combinación sintáctica. En el caso de la diferencia entre oligarquía y democracia, el criterio diferenciador radica en la riqueza (ploutós) y en la pobreza (penía) de los que gobiernan, sean pocos o muchos ${ }^{49}$, si bien estadísticamente serán mayoría los que formen el segundo grupo social.

Estos sistemas aplican cada uno una cierta justicia, que es virtud política. La justicia se define por la igualdad ${ }^{50}$, pero ninguno de ellos alcanza una justicia completa, perfecta, consumada. Todos invocan la justicia absoluta (dikaion légein aplós) pero no puede darse más que una justicia gradual, pues no cabe igualdad absoluta, sin perjuicio de que quepa una igualdad objetiva en función del parámetro designado para darle contenido. Para empezar, la igualdad puede ser entendida según el número y según el mérito, o proporcional $^{51}$. Dada la inconmensurable heterogeneidad de lo real, la justicia absoluta y la igualdad absoluta son conceptos límite. La igualdad es, pues, un concepto sincategoremático. Ha de precisarse, como decimos, el parámetro en función del cual definir la igualdad. Lo igual se dice de lo diferente y, como la justicia, huye de lo absoluto y no puede darse en abstracto, en el vacío metafísico de una entidad trascendente ${ }^{52}$.

Para alcanzar un grado mínimo de igualdad política (isonomía), el Estado debe procurar la virtud política (ciudadana), que no es posible sin la formación de los futuros ciudadanos ${ }^{53}$. Esta cualidad, que constituye el criterio político (legal) de una república (politeía), supera los límites de lo sanguíneo y lo tribal (nobleza), de lo militar y lo económico (oligarquía o plutocracia). La noción aristotélica de amistad política tiene este sentido ${ }^{54}$.

\footnotetext{
Politica, III, 1294a.

Política, IV, 1294b; V, 1309a.

Política, III, 1280a.

“íson tò díkaion einai." (Política, III, 1280a).

Política, V, 1301b. Véase también, Ética Nicomaquea, V 6, 1131a14-b8.

Cf. Fedón, 74a-c, 75c-d, Gredos, trad.: Carlos García Gual; Crátilo, 386d y ss.; 430d.

Sobre la educación en el Estado: Política, III, 1280b; 1331b ss. y el libro VIII.

54 "Es evidente, pues, que la ciudad no es una comunidad de lugar para impedir injusticias recíprocas y con vistas al intercambio. Estas cosas, sin duda, se dan necesariamente si existe la ciudad; pero no porque se den todas ellas ya hay ciudad, sino que ésta es una comunidad de casas y de familias para vivir bien, con el fin de una vida perfecta y autárquica. Sin embargo, no será posible esto si no habitan un mismo lugar [tópos] y contraen entre sí matrimonios [epigamíais]. Por eso surgieron en las ciudades los parentescos, las fratrías, los sacrificios públicos y las diversiones de la vida en común. Todo es obra de la amistad [phylías], pues la elección de la vida en común supone amistad. El fin [télos] de la ciudad es, pues, el vivir bien, y esas cosas son para ese fin. Una ciudad es la comunidad de familias y aldeas para una vida perfecta y autosuficiente, y ésta es, según decimos, la vida feliz y buena." (Politica, III, 1281a).
} 
La pregunta que se impone en este punto es "¿quién debe ejercer la soberanía (kyrión) en la ciudad?", que conduce a la respuesta dada en 1287a: la ley (nómos). En ella reside la clave, a nuestro juicio, de toda la teoría política de Aristóteles ${ }^{55}$.

El alma es principio de vida, función biológica. Por analogía con el organismo vivo, el alma de la ciudad habrá de ser también la función más compleja, la propia de ese individuo compuesto que es el Estado, determinada por su finalidad, por su máximo grado de perfección posible. El alma es la dirección biopolítica de una realidad que no es sólo botánica, no sólo animal, no individual, sino dotada de la capacidad general de identificar los medios adecuados para el fin específico. La racionalidad política es una cualidad común, que rebasa las barreras de lo individual, de lo atómico, de lo idiota. De ahí que no sea posible alcanzar el bien común como télos del Estado si el ejercicio del poder lo monopolizan los apetitos o las pasiones. Los sujetos operatorios que detentan el poder tenderán a entregarse, en su ejercicio, a sus intereses económicos, a la satisfacción de los propios deseos por encima del bien común, o a someterse a sus sentimientos por fidelidad sanguínea, familiar o tribal a costa del beneficio de la sociedad política. Y del mismo modo que en el ámbito del conocimiento teórico habrá de regir la objetividad que la racionalidad humana permite captar, más allá de la opinión (dóxa) y las creencias, impermeables al conocimiento, en lo político no habrá modo de alcanzar siquiera en parte el bien común si no rige la racionalidad común, esto es, la ley, que no puede ser dictada por un poder suprahumano y trascendental, ni podrá ser tampoco fruto arbitrario de la mera convención. Como ya se indicó, el territorio (tópos) y los habitantes son condiciones necesarias pero no suficientes para un Estado. Por lo mismo, la soberanía no puede residir en ellos, como no es propiamente humano, a escala individual, el sujeto que carece o no desarrolla las facultades genéticas que lo distinguen específicamente de lo vegetal y de lo animal. Digamos que, en la escala biológica del sistema aristotélico, una rosa no puede aullar ni el león puede leer a Aristóteles ni ser abogado del Estado.

La racionalidad política, por lo tanto, desborda los individuos hasta llevar a la virtud ciudadana a sujetos mediocres ${ }^{56}$. La ciudad bien organizada es mejor que los individuos mejores tomados aisladamente y que la masa cegada por sus pulsiones, extrañas a la racionalidad de la ley. El buen funcionamiento del Estado hace que las decisiones individuales, que podrán ser más o menos estúpidas o caprichosas, apenas tengan influencia con respecto a la ley, cristalización ajena al tiempo presente, que se da, al menos, a otra escala temporal por estar a salvo de los vaivenes volubles de gobernantes y gobernados. Al estar materializada en instituciones que no se ciñen a las pulsiones de los individuos, la multitud opera según las restricciones comunes que marcan las leyes. En un régimen recto, no deciden los individuos por separado ni la masa de hombres, sino la asamblea como institución por encima de ellos ${ }^{57}$.

Pero la multitud no puede juzgar bien si no es ahormada por la racionalidad política de la ley. En caso contrario, ya advierte Platón que las masas no pueden filosofar $^{58}$. El pensamiento es un ejercicio individual según códigos que son comunes,

\footnotetext{
55 "Es malo que sea un hombre y no la ley quien ejerza la soberanía, estando sujeto a las pasiones que afectan al alma" (Politica, III, 1280b 10).

56 Política, III, $1281 \mathrm{~b}$.

57 "Al ser muchos, cada uno tiene una parte de virtud y de prudencia, y, reunidos, la multitud [pléthos] se hace como un solo hombre con muchos pies y muchas manos y muchos sentidos; así también ocurre con los caracteres [éthe] y la inteligencia [diánoian].” (Política, III, 1281b).

58 República, VI 493a.
} 
que atraviesan al sujeto constituyéndolo y permitiéndole ir más allá de sí mismo. La racionalidad es común y, por eso, no brota de la burbuja del individuo aislado ni de la ceguera del macizo homogéneo de los grupos cerrados ${ }^{59}$. Spinoza emplea una fórmula semejante ${ }^{60}$.

Aristóteles estaría sugiriendo acaso una tendencia teleológica (natural) que persiste en el mesotés, en el punto medio ${ }^{61}$, en ese equilibrio inestable, precario entre el individuo superior pero aislado y el amasijo de la multitud, unido pero cegado. Es la asamblea como institución que opera a través de los ciudadanos, y no todos ellos como conjunto o masa, la que puede juzgar según el bien común. La ley, como racionalidad común, opone resistencia contra las inercias ontológicas a la mediocridad al materializar lo mejor de los individuos tomados en conjunto, a salvo de los peligros de las elites privilegiadas y de las masas ofuscadas. Además, la muchedumbre es más difícil de corromper que unos pocos ${ }^{62}$. Sin embargo, habría que añadir aquí, es más fácil de cegar si no rige la racionalidad política común del rigor de la ley. Desde el punto de vista político y socio-económico podría acaso entenderse como la necesidad de una capa amplia de la población, dotada de cierta confluencia de objetivos, equivalente a una especie de clase media, como elemento primordial sobre el cual se asiente la estabilidad de un Estado, por intereses económicos, formación técnica y académica, educación ciudada$\mathrm{na}^{63}$. Políticas en detrimento de las clases medias, como se viven hoy día en muchos casos, son catastróficas a medio y largo plazo. La dirección vectorial (virtuosa), natural (física) oscila entre los límites patológicos, atomismo y totalitarismo, alejándose de ellos: "cada uno por separado es imperfecto para juzgar." ${ }^{\prime 4}$

En lo relativo a la elección de los magistrados y a la rendición de cuentas, Aristóteles cuestiona la soberanía del pueblo porque requerirían condiciones técnicas específicas de expertos (eidósin) ${ }^{65}$. Por eso, la clave es que la soberanía la ejerce el demos reunido en asamblea (ekklesía), el tribunal (diakosiné) y el consejo (boulé) y no sus componentes individuales, siempre expuestos a buscar el interés propio (idiota) y alejarse del fin político común (koiné) ${ }^{66}$.

En este punto, se entiende la distinción terminológica e histórica en relación con los vocablos demos y pléthos. Si bien demos tiene el sentido originario de muchedumbre o masa de gente, el compuesto demokratía parece proceder de las démos, resultado de la transformación de las tribus, fratrías, clanes y familias en nuevas

59 “cien individuos que, por separado, pueden formar un conjunto distributivo de cien sabios, cuando se reúnen para hacer un manifiesto como el que comentamos, constituyen un conjunto atributivo formado por un único idiota." (BUENO, G., "El Manifiesto de la Alianza de Intelectuales y el «No a la guerra» de los Premios Goya", El Catoblepas, número 12, febrero 2003, pág. 2).

60 "Ubi homines iura communia habent omnesque una veluti mente ducuntur, certum est (per art. 13. huius cap.) eorum unumquemque tanto minus habere iuris, quanto reliqui simul ipso potentiores sunt, hoc est, illum revera ius nullum in naturam habere praeter id, quod ipsi commune concedit ius. Ceterum quicquid ex communi consensu ipsi imperatur, teneri exequi vel (per art. 4. huius cap.art. 13. huius cap.) eorum unumquemque tanto minus habere iuris, quanto reliqui simul ipso potentiores sunt, hoc est, illum revera ius nullum in naturam habere praeter id, quod ipsi commune concedit ius. Ceterum quicquid ex communi consensu ipsi imperatur, teneri exequi vel (per art. 4. huius cap.) iure ad id cogi." (Tractatus Politicus, II, 16).

${ }^{61}$ Política, III, 1287b. Versión aristotélica de la symploké platónica.

62 Política, III, 1286a.

63 Política, III, 1281 b 7; "los buenos y los malos son muy pocos los unos y los otros, y muchísimos los del medio." (PLATÓN, Fedón, 90a).

64 Politica, III, 1281 b 9.

65 Política, III, 1282a.

66 Política, III, 1282a 18. 
circunscripciones administrativas que no tienen ya en cuenta la sangre o la posición económica, llevada a cabo por Clístenes ${ }^{67}$. El démos constituía una institución, una estructura política y jurídica concreta más allá de los sujetos que la componían. El pléthos es la muchedumbre desatada, impulsiva, voluble por heterogénea. Es el nombre que se aplica a una cantidad inconmensurable de subjetividades que, por muy mayoritaria que pudiera llegar a ser, nunca podrá absorber a la totalidad de los habitantes de la sociedad. Los que quedan fuera de la corriente dominante están destinados a ser barridos. La distinción entre pueblo y populacho, que establece Hannah Arendt en su obra sobre los totalitarismos, apunta en esta dirección y sugiere pistas sobre su operatividad política en la Historia ${ }^{68}$.

El corolario necesario no puede ser más que el siguiente: "las leyes bien establecidas son las que deben ejercer la soberanía." Los regímenes que se alejen de este axioma serán desviados y fuente de desastres políticos, caprichos y desigualdades, como la política actual demuestra. Si, como vimos, la prudencia es la virtud política del gobernante, es porque constituye la capacidad para elegir bien los medios orientados al fin del bien común, que es lo que se entiende por justicia: "El bien político es la justicia, es decir, lo conveniente para la comunidad" ${ }^{\prime 69}$ La igualdad da contenido a esta noción de justicia como virtud política, pero, como ya se advirtió, debe ser definida en función de un parámetro concreto. El riesgo en que incurren los sistemas políticos, y no sólo la demagogia, es el igualitarismo: "la igualdad por encima de todo", la igualación indiscriminada puesta en práctica por la institución del ostracismo, empleada también por tiranías y oligarquías ${ }^{70}$. Cuanto más a expensas del capricho de los gobernantes, más alejada de la ley, más perniciosa para el común de la sociedad. Ese componente sentimental en política, del que hay cantidad de ejemplos aun hoy día, retuerce las medidas políticas adoptadas encauzando al Estado hacia su descomposición. La soberanía de la ley, de esa modesta racionalidad común, salva de las políticas patéticas, de la idiotez disfrazada de ideología ${ }^{71}$. De modo que el poder de la ley es la única vía para descontar el componente irracional ${ }^{72}$.

La ecuación que, siguiendo este análisis, corona la argumentación y constituye la máxima crucial en torno a la cual la teoría sobre el poder político de Aristóteles

67 "[Clístenes] Dividió también el país por demos, en treinta partes, diez de los alrededores de la ciudad, diez de la costa y diez del interior, y dando a éstas el nombre de tritís, sacó a la suerte tres para cada tribu, con el fin de que cada una participase de todas las regiones. E hizo conciudadanos de demo a los que habitaban en cada uno, para que no quedaran en evidencia los nuevos ciudadanos al llevar el nombre de la familia, sino que llevase el nombre de los demos." (Constitución de los atenienses, 21, 4).

68 "El populacho es principalmente un grupo en el que se hallan representados los residuos de todas las clases. Esta característica torna fácil la confusión del populacho con el pueblo, que también comprende a todos los estratos de la sociedad. Mientras el pueblo en todas las grandes revoluciones lucha por la verdadera representación, el populacho siempre gritará a favor del "hombre fuerte", del "gran líder". Porque el populacho odia a la sociedad de la que está excluido tanto como al Parlamento en el que no está representado." (ARENDT, H., Los orígenes del totalitarismo, Madrid, Taurus, 2004, I, IV, p. 162).

69 Política, III, $1282 \mathrm{~b}$.

70 Constitución de los atenienses, 22, 3.

71 "Es mejor aquello en que no se da en absoluto lo pasional [pathetikón] que aquello en que es innato [symphyés]. Esto, en efecto, no existe en la ley, en cambio toda alma humana lo tiene necesariamente." Politica, III, 1286 a.

72 "Es preferible que mande la ley antes que uno cualquiera de los ciudadanos, y por esa misma razón, aun si es mejor que gobiernen varios, éstos deben ser establecidos como guardianes y servidores de las leyes. (...) Así pues, el que defiende el gobierno de la ley [nomón arkhein], parece defender el gobierno exclusivo de la divinidad [theón] y de la inteligencia [noún]; en cambio el que defiende el gobierno de un hombre añade un elemento animal; pues tal es el impulso afectivo, y la pasión pervierte a los gobernantes y a los mejores hombres." (Politica, III, 1287a). 
gana toda su potencia es "la ley es razón [noús] sin deseo." fórmula en negativo de la aristotélica para designar su reverso: "una voluntad libre de toda ley." ${ }^{74}$ Es decir, presa de esa maquinaria de servidumbre que es la ilusión de una voluntad libre. De hecho, el gobierno de la voluntad (boulesin), sea de un soberano (tirano), de una élite (oligarcas) o de la multitud (demagogia), es el gobierno de esas pulsiones incontrolables e infrarracionales que apartan del bien común, racionalmente regulado por la impersonalidad de la ley, como la voluntad de hallar 6 sumando 2 más 3 se aleja de la férrea realidad matemática. Lo que quede fuera de la ley es pasto de las desviaciones patológicas de lo político. Por eso, los sistemas en los cuales no rige la ley no deben en rigor ser considerados repúblicas (politeía), es decir, Estados, pues en ellos se imponen criterios prepolíticos. Así pues, "la ley debe gobernarlo todo." 75 Las formas desviadas de gobierno son, por consiguiente, contra naturaleza (parafísicas) ${ }^{76}$. Teniendo a la vista este armazón conceptual, es obligado un vistazo a la categoría política (y biopolítica) de democracia. Es un sistema de una gran precariedad por su complejidad y por residir la soberanía en la mayoría de los habitantes del Estado, que componen una realidad múltiple, heterogénea, dialéctica y voluble que no es asequible por mucho tiempo al sosiego, prudencia y tedio de las políticas racionales que puedan aportar estabilidad a la sociedad. El riesgo de caída en demagogia (populismo) es patente y se decide en el depositario de la soberanía: la ley, impersonal, objetiva, expresión de racionalidad, que no es dogmática pero tampoco caprichosa, o la multitud ${ }^{77}$. Sucede la demagogia cuando se acaba "halagando al pueblo como a un tirano"78. El despotismo de las masas triunfantes ya arrasó la Europa de los años 30 y 40 del siglo XX. El despotismo de la estupidez y del fanatismo vuelven a sacudir los cimientos de una civilización que aun parece envuelta en las ensoñaciones ilustradas que las dos grandes guerras se encargaron de barrer.

Madrid, 28 de marzo de 2016.

73 “áneu órexeos noús ó nómos éstín.” (Politica, III, 1287a).

74 "libera sive omni lege soluta voluntate" (Tractatus Politicus, XI, 2).

75 "deí gàr tòn mèn nómon árchein pánton." (Política, IV, 1292b). Desde coordenadas conceptuales e históricas diferentes, esta máxima recuerda a la noción de Estado Absoluto de Spinoza.

76 Política, III, 1287 y y 1288 a.

77 "Otra forma de democracia es en lo demás igual a ésta, pero es soberano el pueblo y no la ley; esto se da cuando los decretos son soberanos y no la ley. Y esto ocurre por causa de los demagogos. En las ciudades que se gobiernan democráticamente no hay demagogos, sino que los ciudadanos mejores ocupan los puestos de preeminencia; pero donde las leyes no son soberanas, ahí surgen los demagogos. El pueblo se convierte en monarca, uno solo compuesto de muchos, ya que los muchos ejercen la soberanía, no individualmente, sino en conjunto. (...) Un pueblo de esta clase, como si fuera un monarca, busca ejercer el poder monárquico, sin estar sometido a la ley, y se vuelve despótico, de modo que los aduladores son honrados, y una democracia de tal tipo es análoga a lo que la tiranía entre las monarquías. Por eso su carácter es el mismo: ambos regímenes ejercen un poder despótico sobre los mejores." Política, IV, 1292a.

78 Política, II, 1274a. 